\title{
A METHODOLOGY FOR UNDERTAKING VULNERABILITY ASSESSMENTS OF FLOOD SUSCEPTIBLE COMMUNITIES
}

\author{
J. PERDIKARIS, B. GHARABAGHI \& E. MCBEAN \\ School of Engineering, University of Guelph, Guelph, Ontario, Canada.
}

\begin{abstract}
Many factors contribute to a communities' vulnerability with respect to flooding, including its population, built environment, and concentration of wealth in a small number of highly vulnerable areas that are susceptible to flooding. This paper presents a planning and risk management tool for assessing the vulnerability of communities to flooding, using a combination of Monte Carlo Simulation techniques and multi-criteria analysis. This process has been applied to the Credit River watershed, in Ontario, Canada, to assess the vulnerability of the 22 flood damage centres within the watershed. These flood damage centres have been previously identified in the Canada-Ontario Flood Damage Reduction Program Study (1985). A vulnerability characterization of the Credit River watershed was undertaken in 2007, this work builds upon the previous study. The indices developed in this study provide a quantitative measure of the vulnerability for each of the 22 flood damage centres, and they are also used to estimate the total expected annual direct and indirect damage costs for each of the flood damage centres. The indices are also a useful tool for stakeholder consultation and communication, and can be used for water resources, landuse and emergency planning within the watershed.
\end{abstract}

Keywords: damages, flooding, Monte-Carlo, simulation, vulnerability.

\section{INTRODUCTION}

Vulnerability with respect to flooding is defined as the extent to which a community can be impacted by a flood or flooding hazard [1]. Vulnerability can be expressed as a measure of susceptibility (i.e. low, medium, high, and very high) to a flood hazard, or with respect to risk management, it is expressed as the probability that a given vulnerability will succeed given that a flood will occur.

Communities must identify exposure to hazard impacts to proactively address emergency response, disaster recovery, and hazard mitigation, and incorporate sustainable development practices into comprehensive planning. Hazard mitigation, an important part of sustainable development, eliminates or minimizes disaster-related damages and empowers communities to respond to and recover more quickly from disasters [2]. The process of assessing the vulnerability of an area to a flood hazard entails determining the following: Who is vulnerable? What is vulnerable? Where is it located? In determining the vulnerability of a population with respect to flooding, indicators need to be established to identify areas with multiple criteria for assessing vulnerability, which requires specific considerations for the population at risk.

There are many different aspects that can be incorporated into a vulnerability index, such as monetary vulnerability, social vulnerability, criticality, economic vulnerability, environmental vulnerability and critical infrastructure vulnerability. Criticality refers to a communities' accessibility to emergency services such as fire, police, ambulance and medical care. Economic vulnerability is the costs incurred or money lost through loss of production, distribution and consumption. Environmental vulnerability pertains to environmentally sensitive areas (ESAs) that are located within the flood damage centres; areas that have identified as being susceptible to flood waters. From an environmental perspective, naturally occurring floods are not always viewed as a hazard, since they provide 'wash-out' and/or replenishment of sediments for 
aquatic habitat. Critical infrastructure vulnerability is a measure of the effect of damage to critical infrastructure, including telecommunications, electricity, drinking water, and sewer services. Because the later require significant amounts of data to process in order to quantify the vulnerability index, the focus of this paper will be limited to the monetary, social and critical vulnerabilities, the aim of which is to evaluate the vulnerability of a community to flooding using these three criteria.

\section{BACKGROUND INFORMATION}

A disaster occurs only if an extreme event such as a flood strikes a vulnerable population. However, what is meant by vulnerability needs to be specified. In the traditional meaning, a disaster is a state, in which a population, population group or individual is not able to cope or is not able to overcome the adverse effects of an extreme event, without outside help.

When examining extreme events, such as flooding, although the primary cause for a flood is extreme rainfall or snowmelt, or combination of both, the impact or magnitude of a flood is determined by human influences. For example, the definition of a disaster as a state where people at risk can no longer help themselves conforms to the modern view of a disaster as a social event, where people at risk are vulnerable to an extreme event because of their social conditions. According to this view, disaster management is not only a technical task, but also a social task.

People are vulnerable to water-related hazards, specifically, floods. Between 1960 to present, the number of weather-related disasters has been increasing steadily (Public Safety Canada, Disasters Database). In addition, the costs associated with flood damages and weather-related disasters have also been increasing steadily (Public Safety Canada, Disasters Database). For example, in 1997 the Red River floods in Manitoba resulted in 4 deaths and 25,000 people being evacuated. The total cost in damages or losses was estimated to be approximately $\$ 1.0$ billion. The previous year the Saguenay flood resulted in 10 deaths and 15,000 people being evacuated. The total cost in damages was estimated to be $\$ 1.5$ billion. Within Canada, areas which have been designated as 'flood risk' are those with high population densities (Public Safety Canada, Disasters Database), conforming to the modern view of a disaster as a social event.

\subsection{Indicators of vulnerability}

Vulnerability is a function of exposure, sensitivity, and adaptive capacity. Differential vulnerabilities exist across different systems based on inherent response abilities. Both humans and natural systems are affected. The challenge is to define factors (indices) that quantify the impact on human vulnerability of flood disasters, and obtain a quantitative basis for decision making. The United Nations defines this factor as the 'index of human security'.

An indicator, comprising a single data point (or a single variable) or an output value from a set of data (aggregation of variables), is a quantity that describes a system or process such that has significance beyond the face value of its components. It aims to communicate information on the system or process. The dominant criterion behind an indicator's specification is scientific and/or engineering knowledge and judgement [3].

An index is a mathematical aggregation of variables or indicators, often across different measurement units so that the result is dimensionless. The purpose of an index is to provide compact and targeted information for management and policy development and decisions. The problem of combining the individual components is overcome by scaling and weighting processes, which are not absolute, but reflect social preferences [4]. 
According to Green [5], vulnerability is a relationship between a purposive system and its environment, where that environment varies over time. Which environmental perturbations are significant depends on the objectives of the system as only those perturbations that can inhibit the achievement of these objectives are significant. In the past, physical aspects of vulnerability - the spatial distribution of populations and infrastructure in relation to flood hazard - tended to receive more attention in hazards research [6]. But there is now increasing recognition given to the social aspects of vulnerability. For individuals, susceptibility to hazards depends largely on behaviour, well being and the resources people have to enable them to avoid and recover from harm. These, in turn, are largely determined by wider social, economic and political patterns and processes that differentiate how flooding impacts on people and human systems [7, 8]. Analyses of vulnerability increasingly highlight its socially constructed nature [9], underlining the importance of understanding how socio-political processes can create vulnerability and thereby create 'disaster' $[6,10]$.

\subsection{Critical vulnerability}

Vulnerability of a community susceptible to flooding can be defined by three different types: the critical vulnerability, the monetary vulnerability and the social vulnerability. Critical vulnerability focuses on determining the vulnerabilities of key individual facilities, lifelines, or resources within the community. Because these facilities play a central role in disaster response and recovery, it is important to protect critical facilities to ensure that service interruption is reduced or eliminated. Critical facilities include police stations, fire and rescue facilities, hospitals, shelters, schools, nursing homes, and any other structures deemed essential by the community.

\subsection{Monetary vulnerability}

The monetary vulnerability is defined as the cost of damages or the cost of reestablishing previous conditions after a disaster has passed. The monetary vulnerability has well-established methodologies associated with it and has been studied fairly extensively. Generally, flood damage curves are developed from the costs associated with previous events (i.e. FIA curves in the US; or Flood Damage Assessment Curves, Ontario Ministry of Natural Resources) or from extensive interviews with homeowners to identify the type and condition of housing and what would be damaged inside the house at different flood depths [11]. The former approach is likely to underestimate damages as a result of people not accounting for personal time spent cleaning up after a flood, but overestimate damages based on insurance claims from individuals who overstate the damages incurred. The latter approach is labour and time-intensive for data collection and requires people to hypothesise as to their behaviour during a flood event, which may be very different under the stress of the actual situation [12]. Another approach is to use lifestyle classes, rather than residence classes to calculate depth - damage costs [13]. However, the difficulty here has to relate the different lifestyle classes to each flooded residence, a relatively labour and time-intensive task.

The damages due to flooding are usually divided into direct and indirect damages. The direct damages comprise the tangible damages to property that result from contact with or submersion under water, while the indirect damages are as a result of interruption to physical and economic linkages, such as the interruption of traffic flow patterns as a result of a flooded road, and loss of income or business profits [14]. Other approaches have been developed, however they have been deemed too data and computationally intensive to undertake and are 
beyond the scope of this paper. Another intangible flood cost which is not examined herein is anxiety. It has been argued that anxiety affects productivity, which in turn affects Gross National Product (GNP) [15]. Schuster et al. [12] estimated damages due to flooding along the Credit River watershed by estimating the depth of flooding at each structure within each damage centre and converting the depth of flooding to damage cost using the depth-damage curves developed by McBean et al. [11].

\subsection{Social vulnerability}

Social vulnerability is defined as the condition of persons-at-risk, their integration into the community and their access to vital services. Social vulnerability is partially the product of social inequalities to those social factors that influence or shape the susceptibility of various groups to harm and that also govern their ability to respond [16]. It is, however, important to note that social vulnerability is not registered by exposure to hazards alone, but also resides in the sensitivity and resilience of the system to prepare, cope and recover from such hazards [17]. However, it is also important to note, that a focus limited to the stresses associated with a particular vulnerability analysis is also insufficient for understanding the impact on and responses of the affected system or its components.

Two of the principal archetypal reduced-form models of social vulnerability are the Risk-Hazard (RH) model and the Pressure and Release (PAR) model. Initial RH models sought to understand the impact of a hazard as a function of exposure to the hazardous event and the sensitivity of the entity exposed [17]. Applications of this model in environmental and climate impact assessments generally emphasized exposure and sensitivity to perturbations and stressors $[18,19]$ and worked from the hazard to the impacts [17]. The model does not address the distinction among exposed subsystems and components that lead to significant variations in the consequences of the hazards, or the role of political economy in shaping differential exposure and consequences [20,21]. This led to the development of the PAR model.

The PAR model understands a disaster as the intersection between socio-economic pressure and physical exposure. Risk is explicitly defined as a function of the perturbation, stressor, or stress and the vulnerability of the exposed unit [20]. In this way, it directs attention to the conditions that make exposure unsafe, leading to vulnerability and to the causes creating these conditions. Used primarily to address social groups facing disaster events, the model emphasizes distinctions in vulnerability by different exposure units such as social class and ethnicity. The model distinguishes between three components on the social side: root causes, dynamic pressures and unsafe conditions, and one component on the natural side, the natural hazards itself. Principal root causes include 'economic, demographic and political processes', which affect the allocation and distribution of resources between different groups of people. Dynamic pressures translate economic and political processes in local circumstances (e.g. migration patterns). Unsafe conditions are the specific forms in which vulnerability is expressed in time and space, such as those induced by the physical environment, local economy or social relations [20]. Although explicitly highlighting vulnerability, the PAR model appears insufficiently comprehensive for the broader concerns of sustainability science [17]. The model also tends to underplay feedback beyond the system of analysis that the integrative RH models included [18].

Dwyer et al. [22] undertook detailed questionnaires to identify and quantify factors that contribute to vulnerability to a natural hazard. Fifteen rules were identified that lead to characterization of vulnerability. These rules were applied using synthetic population 
estimation in order to generate vulnerability maps for different scenarios. The scenarios were based on severity of injury and direct damages to homes given a damage event. Age, income, gender, employment, residence type, household type, tenure type, health insurance, house insurance, car ownership, disability, English language skills, debt/savings were identified as playing a role in household vulnerability.

Complete destruction of a residence is the great equalizer, making everyone vulnerable. Apart from this, the rules demonstrated that it is a combination of attributes which make a person/household vulnerable. The relative importance of individual indicators was such that injuries, followed by damage to the house, were at the top. House insurance, income and tenure type were next, followed by age, while household type, health insurance, residence type, gender and disability were the lowest scoring indicators [22]. Figure 1 demonstrates the social vulnerability model used in the study by Dwyer et al. [22]. De Almeida et al. [23] depict social vulnerability using a different approach (Fig. 2).

Vulnerability indices may assume a variety of formats. Relevant indices can be aggregated to form a single index or separate indices can be developed which represent different vulnerabilities. Additionally, an index can be constructed through geographical groupings, or by profiling individual geographic entities [24]. The Social Flood Vulnerability Index (SFVI) [25] is a composite additive index which incorporates both social characteristics and financialdeprivation indicators. The Tapsell et al. [25] study based on analysis of other studies undertaken in the UK identifies age and financial status as common key indicators. The Townsend Index [26] was used to identify financially deprived households. Another financial deprivation index is the Carstairs Index [27] which incorporates car ownership, household crowding, unemployment and a social class variable.

The SFVI consists of the Townsend Index, weighted at 0.25 , a 'long-term sick' variable (residents with limiting, long-term illness as a percentage of the population), single parents and, the elderly (age 75 and over). The final index is calculated by summing the standardized Z-scores.

Rygel et al. [28] used poverty, gender, race and ethnicity, age, and disabilities to develop a vulnerability index. Composite indices can have inherent problems. When averaging

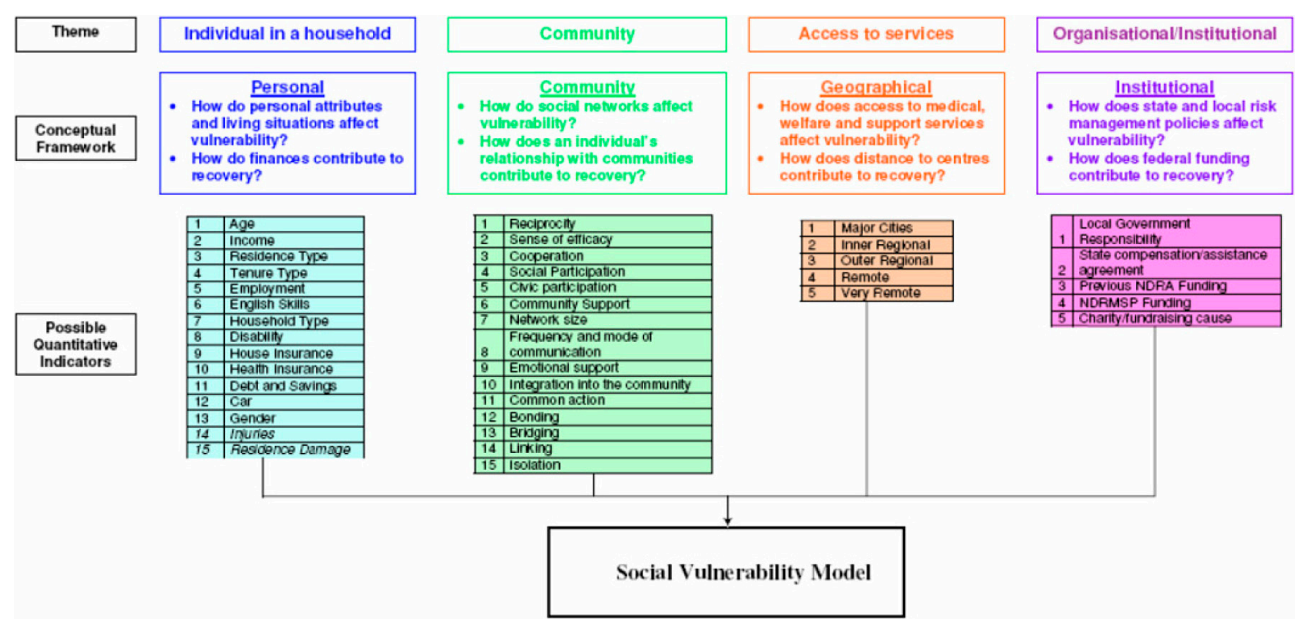

Figure 1: Factors associated with social vulnerability [22]. 


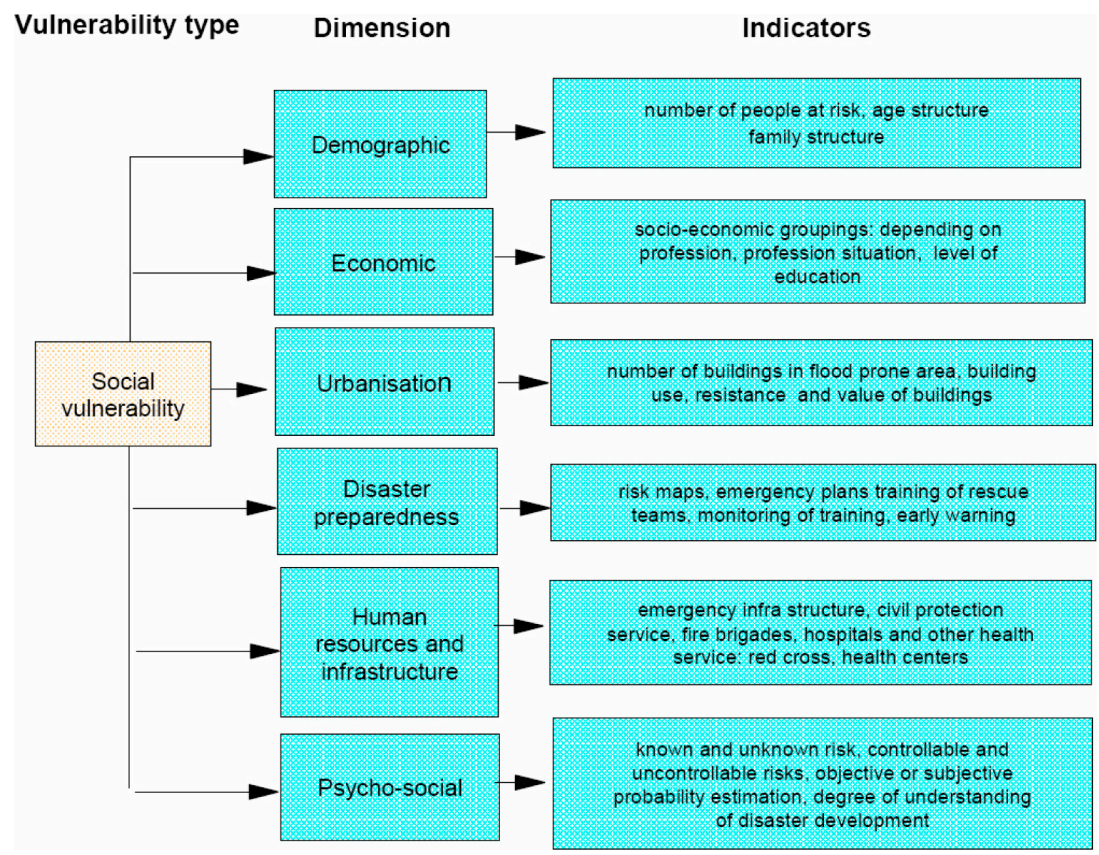

Figure 2: Dimensions and indicators of vulnerability [23].

factors, the importance of an individual factor is reduced and an overall index may classify an area as 'not vulnerable', while an individual factor may indicate 'extreme vulnerability'. When weighting factors, it is difficult to identify the weights to be applied. The assignments can be subjective, relying on expert judgement, rather than quantitative. Additionally, weights cannot account for variations in relative importance of factors over space and time. In order to avoid the problems associated with averaging or weighting, a method was developed which undertook principle component analyses on 57 variables. The top three components that were used in the development of the index can be described as poverty, immigrants and old age/disabilities. To avoid averaging the three parameters for each geographic area, Pareto rankings were used to classify the regions according to the significance of all three components.

St. Bernard [29] includes life expectancy at birth, security, social order and governance indicators, for example, indictable crimes per 100,000 population, resource allocation indicators, for example, the proportion of children belonging to the poorest quintiles, and communications architecture, for example, computer literacy rate.

Health is an important aspect of vulnerability. After a flood event, individual health can be affected by the stress and trauma associated with loss of possessions. Enteric illnesses can be prevalent, given exposure to contaminated water. Cramped conditions in evacuation shelters increase transmission of these illnesses. General damp conditions and the growth of mould on affected surfaces can exacerbate chest conditions, including asthma. It can be difficult to obtain appointments for, or travel to, physician's offices and this can escalate underlying conditions $[12,25]$.

Schuster et al. [12] used the following indicators for characterizing the vulnerability of flood damage centres along the Credit River: household income; persons 65 years and older 
living alone; persons 65 years and older living with relatives; children under 6 years of age; single parents; first language being neither English or French; and secondary school education. Weightings assigned to each indicator were based on three scenarios: no weighting, weightings derived from the literature and weightings derived from a survey questionnaire submitted to professionals asking them to rank each variable. The results of the survey were summed and represented as a ratio of the average. The spatial variations and differences in the numerical value of the vulnerability index between the three weighting schemes; provided a sensitivity analysis of vulnerability scores, as well as identifying vulnerable flood damage centres within the Credit River watershed.

A common theme among the different studies for weighing the indicators of social vulnerability is that the approach itself is relatively subjective since it is based on professional opinion or judgement and is therefore, inherently bias. Some authors criticize the conceptualization of social vulnerability for overemphasizing the social, political and economical processes and structures that lead to vulnerable conditions. Inherent in such a view is the tendency to understand people as passive victims [21] and to neglect the subjective and intersubjective interpretation and perception of disastrous events. Bankoff criticizes the very basis of the concept, since in his view it is shaped by a knowledge system that was developed and formed within the academic environment of western countries and therefore inevitably represents values and principles of that culture. According to Bankoff, the ultimate aim underlying this concept is to depict large parts of the world as dangerous and hostile to provide further justification for interference and intervention [30].

\section{METHODOLOGY}

The Credit River watershed (Fig. 3) lies within the most densely populated region of Canada. The drainage area of the Credit River watershed is approximately $1000 \mathrm{~km}^{2}$. The main branch of the Credit, which originates north of Orangeville and flows southerly to its terminus at Lake Ontario, is over $90 \mathrm{~km}$ in length. Tributaries of the Credit exceed $1500 \mathrm{~km}$ in length. Historically, the Credit River watershed has experienced flood conditions, primarily during the spring conditions. Records of flooding exist from 1797 with 54 recorded floods occurring over a span of 160 years [31]. The Flood Damage Reduction Study carried out by the Credit Valley Conservation Authority (1982-1985) identifies 22 flood damage centres, which involve commercial and residential structures. According to the study flood damages begin at the 5-year design event level for 16 out of the 22 flood damage centres. The study also provides floodlines and flood damage estimates for each of the 22 damage centres. All of the flood damage centres are located within areas of historic development and although the majority of the development is located within the lower reaches of the watershed, flood damage centres are distributed throughout the watershed.

Data analyses for this study were undertaken using a Microsoft Excel spreadsheet (2007). The study used social and economic data at the dissemination area level in conjunction with hydrologic data from Floodline Mapping Study [32] for the Main Branch of the Credit River watershed and from the Flood Damage Reduction Program Study, FDRP [33]. The data were collated to provide an overall vulnerability assessment for each dissemination area affected by flooding at each of the flood damage centres.

The Flood Damage Reduction Study [33] identified 22 flood damage centres. Within each of these damage centres, buildings susceptible to flooding were highlighted and relevant parameters including first floor elevation, lowest opening elevation and building type were also recorded into a spreadsheet database. In order to obtain flooding levels for buildings, the closest upstream cross-section was identified from either the 2007 Floodline Mapping Study of the 
Credit River or the 1985 Flood Damage Reduction Study. For damages along the main branch of the Credit River the 2007 study was used; for damages along the major tributaries the 1985 Flood Damage Reduction Study was used. If there was a large distance between cross-sections and/or significant changes in surface water elevations, the closest cross-section upstream of the damage area was used. Each cross-section has associated surface water elevations for five standard return periods (5 years through to the regional storm event, Hurricane Hazel) which were derived through hydraulic analysis of the channels within the US Army Corps of Engineers HEC-RAS and/or HEC-II models. The buildings within a given damage centre were indexed with respect to the representative reaches and the corresponding flood levels were matched for each return period. For main branch of the Credit River the HEC-RAS model from the 2007 Floodline Mapping Study of the Credit River was used; for the major tributaries the HEC-II model from the 1985 Flood Damage Reduction Study was used.

Flood depth-damage curves developed by McBean et al. [11] were used to estimate costs of flooding based on the depth of inundation at each structure. The building types from the 1985 Flood Damage Reduction Study were converted to the appropriate classes as per McBean et al. [11] flood damage curves, as the former are US based flood damage curves and the latter were developed using Canadian data. McBean et al. [11] subdivided each building class into low, medium and high quality. Information regarding the quality of each structure does not exist in the 1985 Flood Damage Reduction Study or the 2007 Floodline Mapping Study of the Credit River; therefore, three separate flood damage cost estimates (low, medium and high) were determined for each structure. The curves are inherently non-linear when examined as a whole, but each graph is composed of small linear segments. Piece wise linear interpolation was used to determine the cost in damages for each structure based on the depth of flooding.

To determine the actual damage incurred by an event, the lowest opening elevation of the building is compared against the relevant water surface elevation for the various flood scenarios. If the water surface elevation exceeds the lowest opening elevation for the structure, damage will occur. Various factors, including building type, commercial enterprise and size determine the shape of the flood-damage curve. The depth of flooding relative to the first floor elevation is calculated using eqn (1) and non-linear piecewise interpolation is then employed to determine the actual cost in damages at the structure.

$$
F D E=F F E-S W E, \text { if }(L O E-S W E)>0
$$

where FDE is the flood depth relative to the first floor elevation (FFE) of the building, SWE is the upstream water surface elevation for a given flood scenario, and LOE is the lowest opening elevation of the building or structure. The value of FDE is used to estimate the damage cost for a specific building type and flood scenario.

The total damages for each damage centre were determined by summing the individual damage costs for each structure within a damage centre. The flood damage costs for each damage centre were ranked based on a score of $0-4$. These ranked scores represent the vulnerability index for each damage centre. Table 1 lists the score categories and their associated definition of vulnerability. The vulnerability index at each damage centre with respect to monetary damages or direct damage costs incurred by flooding was determined by multiplying the ratio of the 'total cost in damages at each damage centre' to the 'maximum cost in damages for all damage centres' by four.

The social vulnerability used in this study is derived from various references and Monte Carlo simulation. The index is constrained by data availability. For example, in addition to 
the elderly, individuals suffering from mental or physical disabilities or those without a fixed address are potentially more vulnerable. Without access to information regarding these population groups, it is impossible to include them within an index. Table 2 identifies the variables that are included in the vulnerability index as used herein.

Each census category was taken as a ratio to the maximum population for that category living within the flood damage centres. The vulnerability index for each category was determined by multiplying the ratio by four. Census information was derived from the 1996, 2001 and 2006 census data. There has not been any new development within the Regulatory Floodplain of the Credit River since the implementation of the regulations in 1973 under the Conservation Authorities Act. The number of buildings within the Regulatory Floodplain has remained the same. However, changes in population dynamics would not have remained static and therefore, vulnerability indices (VI) were established each census time period.

Weightings $(\gamma)$ were assigned to each census category (eqn (2)). In total there are nine separate variables for estimating the social vulnerability for each damage centre. The weighting assigned to each variable can be expressed as a fraction from 0 to 1 . A weighting value of 1 assigned to any variable means that the total weighting for determining the overall social vulnerability index is carried by that single variable alone. A value of $0.111(1 / 9)$ means that the weightings are uniformly distributed across all categories. Monte Carlo simulation was

Table 1: Vulnerability indices.

\begin{tabular}{ll}
\hline Score & Vulnerability \\
\hline $0>$ and $\leq 1$ & Very Low \\
$1>$ and $\leq 2$ & Low \\
$2>$ and $\leq 3$ & Medium \\
$3>$ and $<4$ & High \\
$=4$ & Very High \\
\hline
\end{tabular}

Table 2: Census categories.

\begin{tabular}{ll}
\hline Parameter & \multicolumn{1}{c}{ Definition } \\
\hline Age $>64$ & $\begin{array}{c}\text { Persons } 65 \text { years and over living with } \\
\text { dependents } \\
\text { Persons } 65 \text { years and over living alone }\end{array}$ \\
Age $>64$ and living alone & Number of children four and under \\
Age $\leq 4$ & Single mother with dependents \\
Single mother with dependents & Single father with dependents \\
Single father with dependents & Number of people who have graduated high \\
Secondary School education or lower & school and those who have not \\
First language is neither English & Number of persons whose first language is \\
nor French & neither French nor English \\
Average Household income & Average annual combined household income \\
Average Value of Home & Average value of a home \\
\hline
\end{tabular}


used to determine the actual weightings. The Monte Carlo method is based on the generation of multiple trials to determine the expected value of a random variable. The basis for the method is provided by eqn (3).

$$
\begin{gathered}
V I s=V I_{1} \gamma_{1}+V I_{2} \gamma_{2}+V I_{3} \gamma_{3}+\cdots+V I_{n} \gamma_{n} \\
\operatorname{Pr}\left\{\mid \frac{1}{N} \sum_{N} \varepsilon-\mu \|<\frac{3 \sigma}{\sqrt{N}}\right\} \approx 99.8 \%
\end{gathered}
$$

The Monte Carlo method provides an estimate of the expected value of a random variable (weightings, $\gamma$ ), and also predicts the estimation error $(\varepsilon)$, which is proportional to the number of iterations $(N)$. The total error is given by eqn (4), where sigma $(\sigma)$ is the standard deviation of the random variable, and $N$ is the number of iterations. The upper bound of $\sigma$ can be estimated by calculating the standard deviation of the maximum, minimum and average values of the random variable. The number of iterations for an error of less than $2 \%$ was determined. A gross estimation of the random variable is the average of the maximum value and the minimum value. An absolute error of $2 \%$ is the average divided by 50 . The random variable was generated a total of 9074 times. The average, median, standard deviation, maximum and minimum values were determined for the entire population of the random variable $(\gamma)$, the results are illustrated in Table 3. Nine separate distributions of the random variable $(\gamma)$ were determined. The average value of the entire population of the random variable $(\gamma)$ was selected as the maximum value of the weighting $(\gamma)$ within the distribution series. The sequences for the different distributions are listed in Table 4. Subsequent values in the distribution series were determined using a logarithmic decay on either side of the maximum weighting $\left(\gamma\right.$ ) value (eqn (5)). Where $\gamma_{n}$ is the value of the weighting $(\gamma)$ at nth position (1-9) within the distribution series, $\mu$ is the maximum value of the weighting $(\gamma)$ within the distribution series, and SQN is the sequence position number (1-9) within the distribution series.

$$
\varepsilon=\frac{3 \sigma}{\sqrt{N}}
$$

Table 3: Random variable statistics entire population group.

\begin{tabular}{ll}
\hline Parameter & Value \\
\hline Population $(N)$ & 9074 \\
Maximum & 0.889 \\
Minimum & 0.111 \\
Average & 0.500 \\
Median & 0.499 \\
Standard deviation $(\sigma)$ & 0.225 \\
Error $(\varepsilon)$ & 0.007 \\
\hline
\end{tabular}


Table 4: Sequence numbers for distribution series.

\begin{tabular}{|c|c|c|c|c|c|c|c|c|c|}
\hline Number & & & & & ues & & & & \\
\hline 1 & 1 & 2 & 3 & 4 & 5 & 6 & 7 & 8 & 9 \\
\hline 2 & 2 & 1 & 3 & 4 & 5 & 6 & 7 & 8 & 9 \\
\hline 3 & 3 & 2 & 1 & 4 & 5 & 6 & 7 & 8 & 9 \\
\hline 4 & 6 & 5 & 4 & 1 & 2 & 3 & 7 & 8 & 9 \\
\hline 5 & 6 & 5 & 4 & 2 & 1 & 3 & 7 & 8 & 9 \\
\hline 6 & 6 & 5 & 4 & 3 & 2 & 1 & 7 & 8 & 9 \\
\hline 7 & 9 & 8 & 7 & 6 & 5 & 4 & 1 & 2 & 3 \\
\hline 8 & 9 & 8 & 7 & 6 & 5 & 4 & 2 & 1 & 3 \\
\hline 9 & 9 & 8 & 7 & 6 & 5 & 4 & 3 & 2 & 1 \\
\hline
\end{tabular}

The overall social vulnerability index was calculated for each of the distribution series, 1-9. The social vulnerability index is independent of the magnitude of the flood since all households and/or businesses within a flood susceptible area will be impacted to some level or degree during an extreme event regardless of its magnitude. Therefore, the social vulnerability index was calculated for the entire flood damage centre and not for any one specific flood event.

Access to emergency services during a flood event is critical. The critical vulnerability was determined for each damage centre. Buffers of $1 \mathrm{~km}$ and $5 \mathrm{~km}$ were placed around each flood damage centre and the number of emergency facilities and/or services within each buffer were counted. Emergency services included the following facilities and/or services: police and fire stations, hospitals, health care services, health care facilities and St. John Ambulance stations. The inverse distance square method was than utilized to determine the average number of facilities and/or services in close proximity to each flood damage centre. The $1 \mathrm{~km}$ radius was chosen to represent a distance which could be completed on foot or in a boat in a timely manner, whether access routes were flooded or not. Either an individual could be transported and/or walk that distance or a rescue team could respond to the emergency relatively quickly. The $5 \mathrm{~km}$ radius is used to depict the portion of the catchment which is within access of emergency services assuming that road transportation is not completely prevented. The critical vulnerability index for each damage centre was determined by multiplying the ratio of the 'total number of emergency services in close proximity to a flood damage centre' to 'the maximum number of facilities in close proximity to a flood damage centre within the Credit River watershed', by 4 . This value was in turn subtracted by 4 to determine the vulnerability index of the flood damage centre with respect to critical facilities.

The total vulnerability index for the flood damage centres was estimated by applying weighting factors $(\gamma)$ to the monetary vulnerability, social vulnerability and critical vulnerability. Monte Carlo simulation was used to estimate the weighting factors. The weighting factors $(\gamma)$ were estimated using the same methodology used to estimate the weighting factors for the social vulnerability index. The difference being that three distribution sequences were used to determine the weighting factors for the total vulnerability index as opposed to nine that were used to determine the social vulnerability index. 
The risk index for each of the damage centre was computed by taking the product of the probability of that an event of magnitude $x$, will occur in any given year over a period of $n$, years and the vulnerability of the damage centre that would result from that event (eqns (6) and (7)). According to eqns (6) and (7), $P\left(X \geq x_{T}\right)$ is the probability that event $X$ of magnitude $x_{T}$ will be exceed in any given year; $T$ is the return period; $n$ is the expected life of the damage centre when the return period $T$ is exceeded; $R$ is the probability that an event $x \geq x_{T}$ will occur at least once in $n$ years; and RI is the risk index. An $n$ value of 25 years was used to compute the risk index for the flood damage centres.

$$
\begin{gathered}
R=1-\left(1-P\left(X \geq x_{T}\right)\right)^{n} \\
R I=R \times(V I)
\end{gathered}
$$

The total flood damage costs were determined for each flood damage centre by converting the total vulnerability index for the flood damage centre into a dollar value. This was done by dividing the vulnerability index by 4 and multiplying by the 'maximum cost in damages for all damage centres'. The annual expected damage cost and the mean annual expected damage risk cost (DRC) were calculated for each return period and for each flood damage centre using eqns (8)-(10). According to eqns (8) and (9), $D_{T}$ is the expected annual damage cost and $\Delta D_{i}$ is the incremental expected damage cost.

$$
\begin{gathered}
D_{T}=\sum_{i=1}^{\infty}\left[\frac{D\left(x_{i-1}\right)+D\left(x_{i}\right)}{2}\right]\left[P\left(x \geq x_{i-1}\right)-P\left(x \geq x_{i}\right)\right] \\
\Delta D_{i}=\left[\frac{D\left(x_{i-1}\right)+D\left(x_{i}\right)}{2}\right]\left[P\left(x \geq x_{i-1}\right)-P\left(x \geq x_{i}\right)\right] \\
D R C=D_{T}-\Delta D_{i}
\end{gathered}
$$

\section{RESULTS AND DISCUSSION}

The direct costs or monetary damages were estimated for the Regulatory event (Hurricane Hazel), and the 5-100-year events. In total, there are 1312 buildings located within the regulatory floodplain along the Credit River, 1222 of which are residences. Out of the 1312 buildings within the regulatory floodplain, 678 are impacted by flooding under Regulatory flood conditions. Out of the 678 buildings that are impacted by flooding, 644 are residences. The maximum flood depth estimated along the Credit River under regulatory flood conditions was $4.46 \mathrm{~m}$, the minimum was $0.1 \mathrm{~m}$. The depths of flooding along the Credit River for the regulatory event were segregated into five separate groupings. These groupings were based on the vulnerability index score categories listed in Table 1. A summary of the number of buildings and residences impacted by flooding for the various flood depth groupings are listed in Table 5. According to Table 5, 56\% of residences and/or buildings experience flooding in the range of $0-1.12 \mathrm{~m}, 32 \%$ experience flooding in the range of $1.12-2.23 \mathrm{~m}, 10 \%$ experience flooding in the range of 2.23-3.35, less than $2 \%$ experience flooding in the range of 3.35-4.46 m and less than $1 \%$ experience flooding of $4.46 \mathrm{~m}$ or greater. 
Figure 3 illustrates the vulnerability index with respect to monetary damages or direct damage costs incurred by flooding. The monetary vulnerability indices illustrated in Fig. 3 represent the cost in damages that would be incurred by the regulatory event or Hurricane Hazel. The direct costs in damages to buildings as a result of flooding are calculated on the basis of the quality or class of the structure, high, medium or low. Since, this information was not available, three separate flood damage cost estimates (low, medium and high) were determined for each structure. According to Fig. 3, with exception of 2 out of the 22 flood damage centres, the quality or class of the structures has very little impact on the monetary vulnerability index of the flood damage centre.

Figures 4-6 illustrate the social vulnerability indices for the following census periods: 1996, 2001 and 2006. According to Figs 4-6, there is no difference in the social vulnerability indices for the different census periods, suggesting very little change in the population dynamics within the various flood damage centres over the last 10 years.

Figure 7 illustrates the critical vulnerability index for the various flood damage centres within the Credit River watershed. According to Fig. 7, for the more rural areas particularly

Table 5: Summary of buildings and flood depths within the floodplain.

\begin{tabular}{|c|c|c|c|c|c|c|c|}
\hline & \multirow[b]{2}{*}{$\begin{array}{c}\text { Total no. of } \\
\text { buildings }\end{array}$} & \multirow{2}{*}{$\begin{array}{c}\text { Total no. of } \\
\text { buildings } \\
\text { flooded }\end{array}$} & \multicolumn{5}{|c|}{$\begin{array}{l}\text { No. of buildings within each flood } \\
\text { depth grouping }\end{array}$} \\
\hline & & & $\begin{array}{c}0.00- \\
1.12\end{array}$ & $\begin{array}{l}1.12- \\
2.23\end{array}$ & $\begin{array}{c}2.23- \\
3.35\end{array}$ & $\begin{array}{c}3.35- \\
4.46\end{array}$ & 4.46 \\
\hline All structures & 1312 & 678 & 380 & 218 & 68 & 12 & 2 \\
\hline Residences & 1222 & 644 & 362 & 208 & 63 & 9 & 2 \\
\hline
\end{tabular}

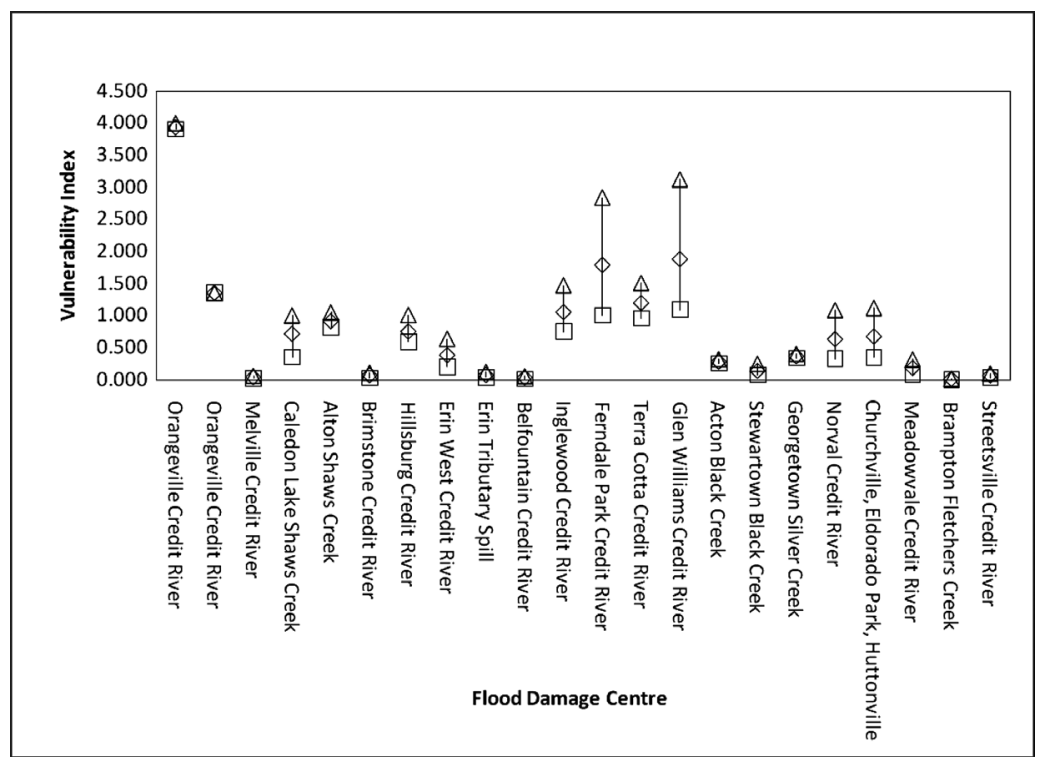

Figure 3: Monetary vulnerability index, Credit River watershed. 


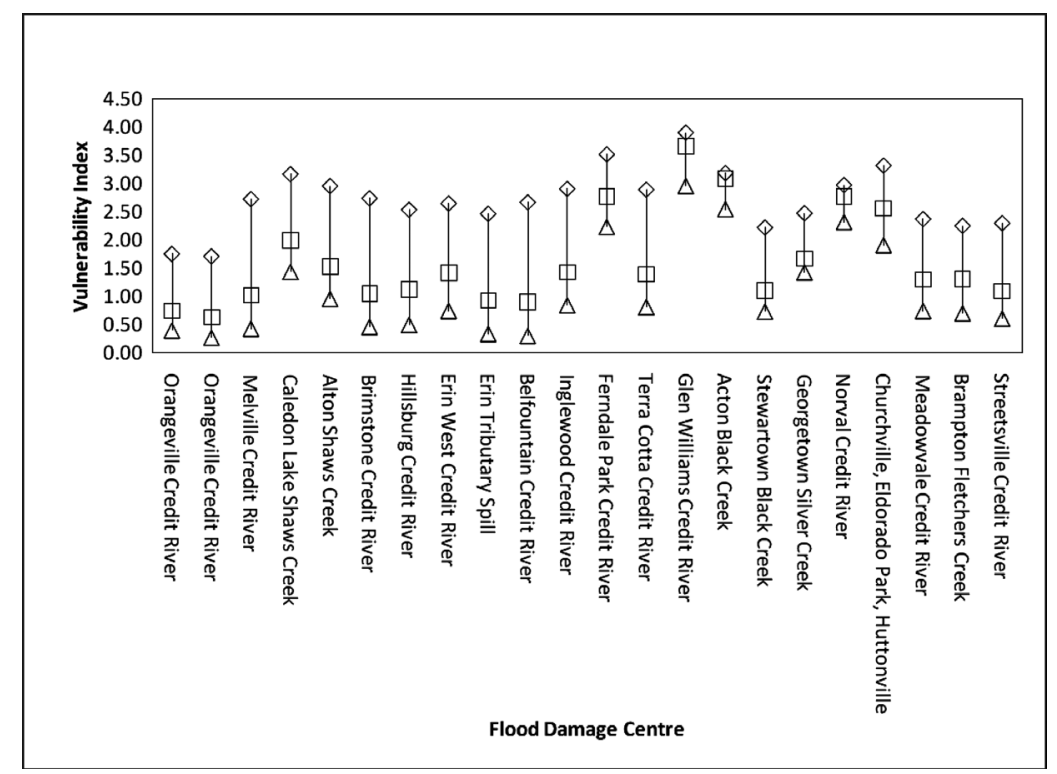

Figure 4: Social vulnerability index, Credit River watershed 1996 census data.

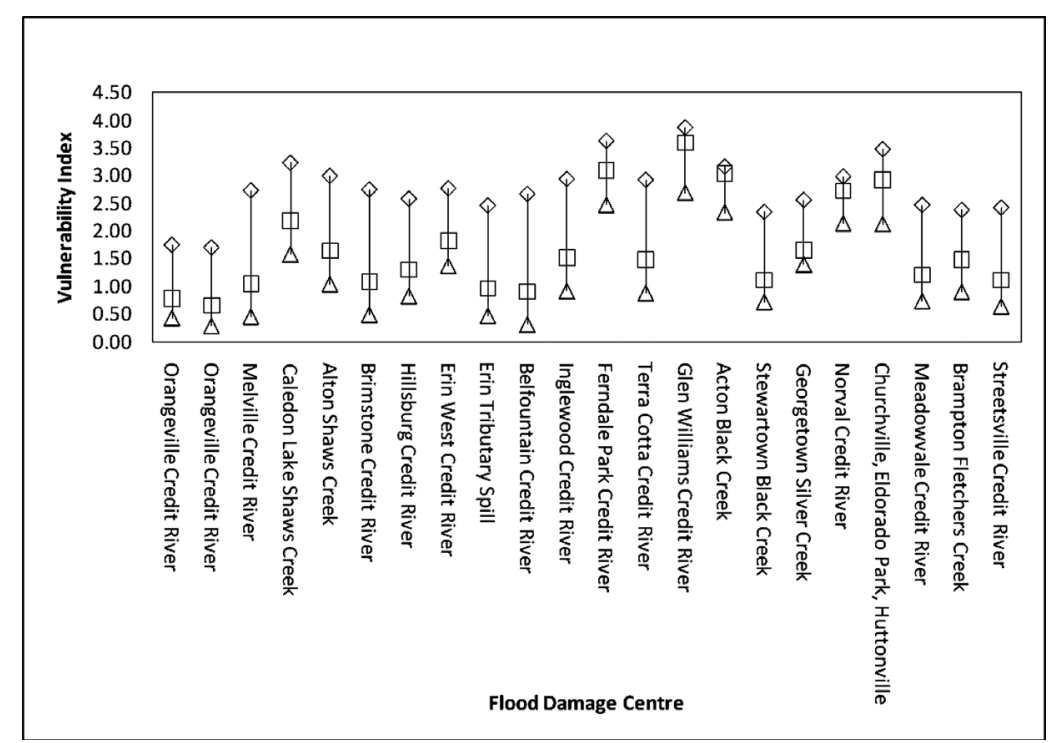

Figure 5: Social vulnerability index, Credit River watershed 2001 census data. 


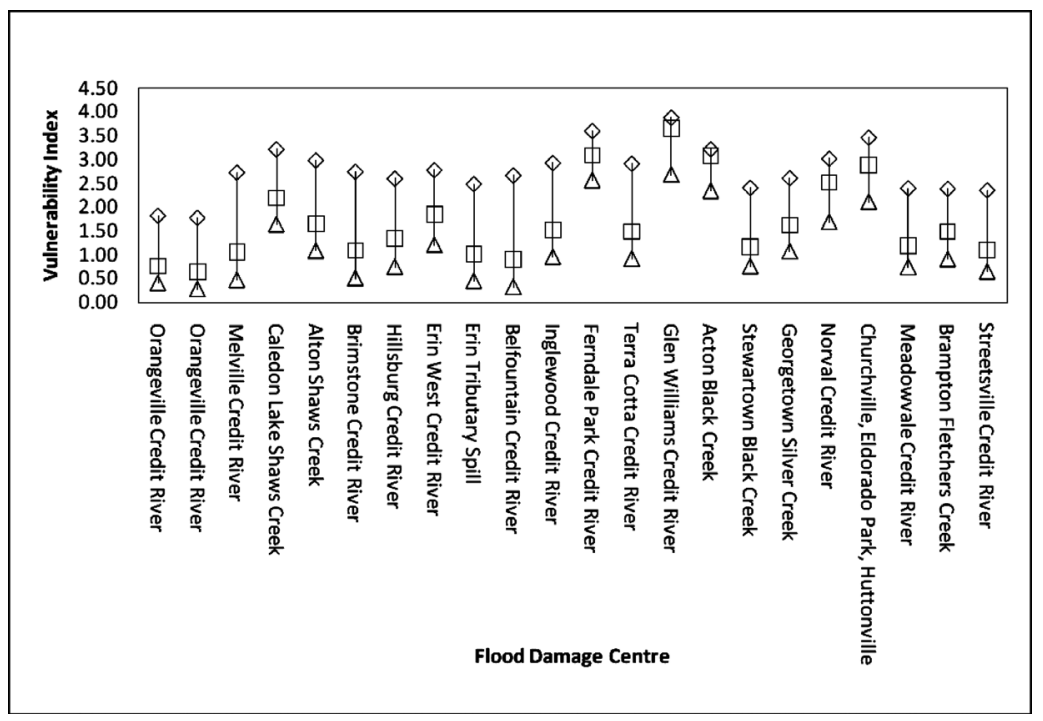

Figure 6: Social vulnerability index, Credit River watershed 2006 census data.

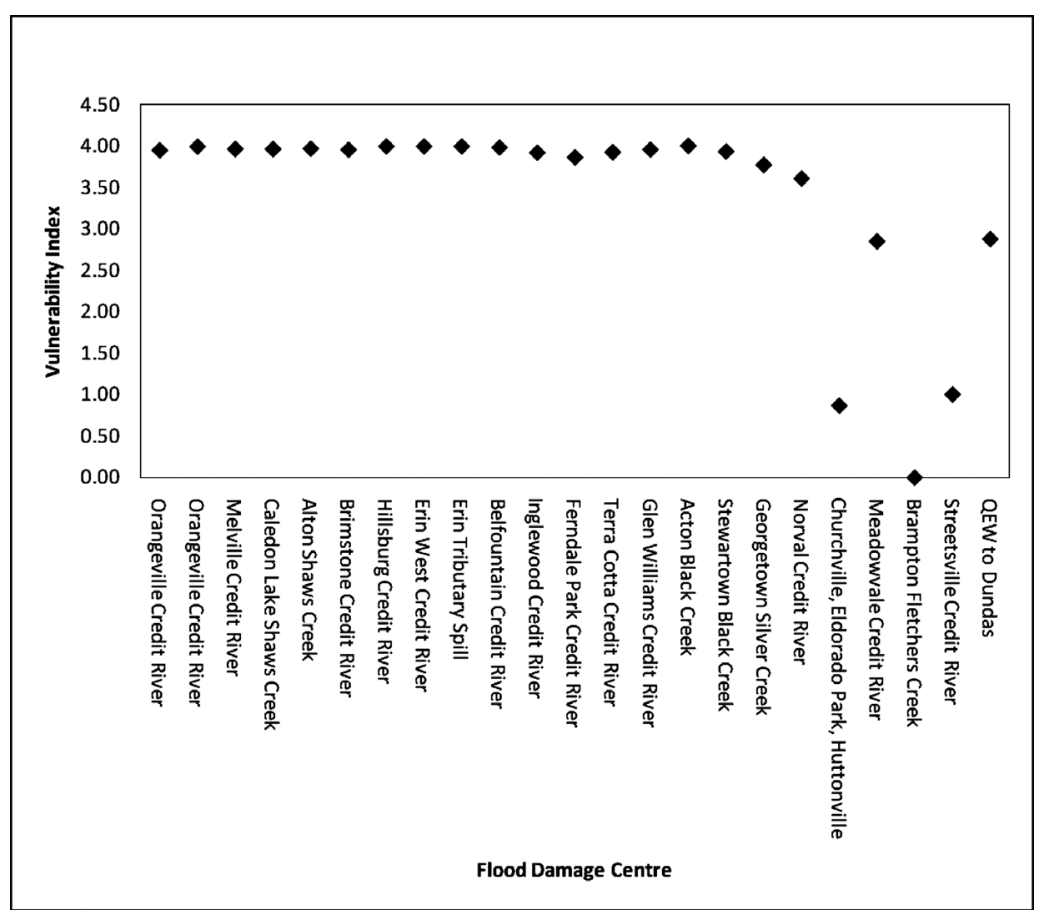

Figure 7: Criticality vulnerability index, Credit River watershed. 
in the mid and upper portions of the watershed access and proximity to emergency services are sparser and are therefore, ranked higher. Whereas, for the more densely populated areas of Mississauga and Brampton access to emergency services such as hospital and ambulatory care are readily available and are in close proximity to the flood damage centres.

Figure 8 illustrates the overall vulnerability indices for the various flood damage centres along the Credit River watershed. Comparisons were made between the vulnerability indices for the flood scenarios and/or events, for example, regulatory event (Hurricane Hazel) and the 5-100-year events. No differences were observed between the vulnerability indices for the different flood events. Therefore, suggesting that the vulnerability index is independent of the magnitude of the event when considering other factors including social status and proximity to emergency services.

Figure 9 illustrates the direct costs and direct and indirect costs as a result of flood damages for varying return period flood events. According to Fig. 9, the cost in flood damages increases with respect to the return period of the event, indicating the greater the magnitude of the event the greater the impact to the community. Wu et al. [34] showed that a rise in water level could increase the vulnerability of a community to flood hazards considerably by increasing the areas that are exposed to the highest flood risk, hence increasing the number of critical facilities, properties, and people to the risk of flooding. However, the relationship between the cost in damages and the return period is not linear but logarithmic, suggesting that for the more extreme and less frequent events, such as the 100-year event or greater, the impacts to the community are so severe that any increase in the magnitude of the event would be indifferent to the cost in damages. In addition, within each flood damage centre, there is limited number of buildings and therefore, the level of damage to these structures is also limited.

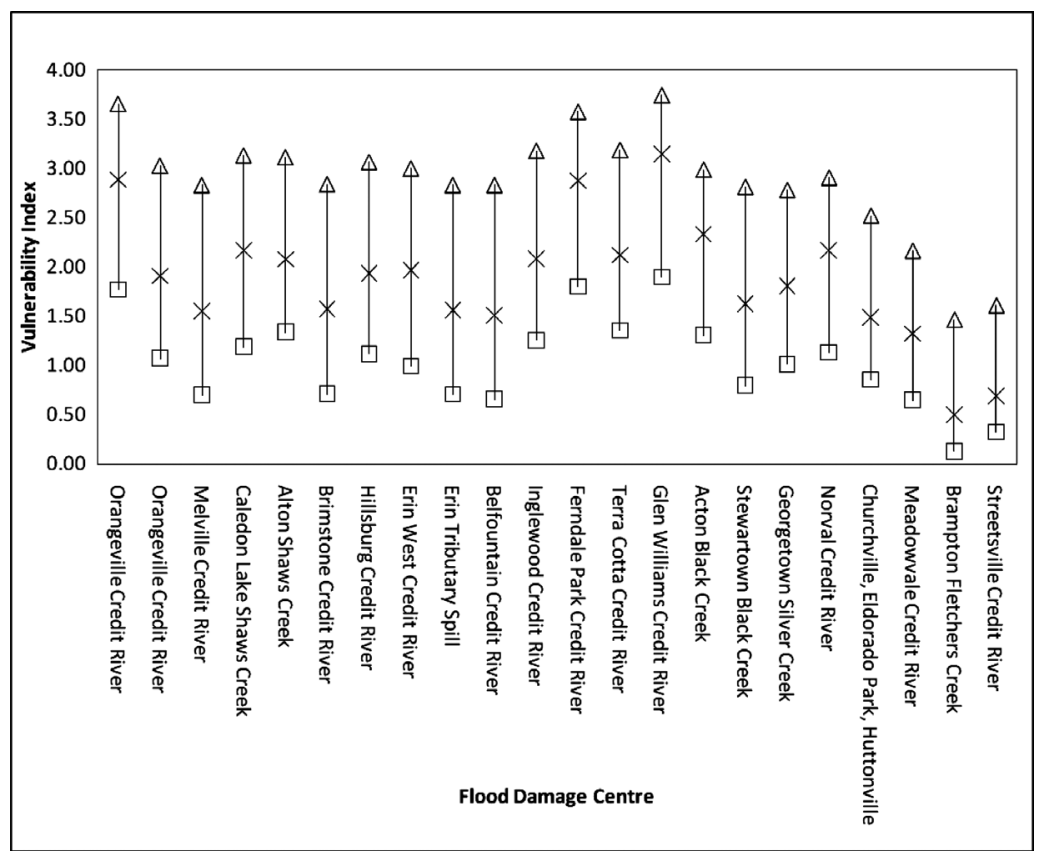

Figure 8: Vulnerability index, Credit River watershed. 
In the worst case scenario this would mean complete destruction of all structures with the floodplain. Furthermore, the direct and indirect flood damage costs are four times the direct flood damage costs for the various return period flood events, indicating the level of impact indirect costs can have on total flood damage costs.

Figure 10 illustrates the mean annual expected flood damage costs for the Credit River watershed. According to Fig. 10, the mean annual expected flood damage costs for direct and indirect flood damages incurred can range anywhere from 2 to 5 times the direct damage costs. These values represent the average annual costs of flood damages over many years,

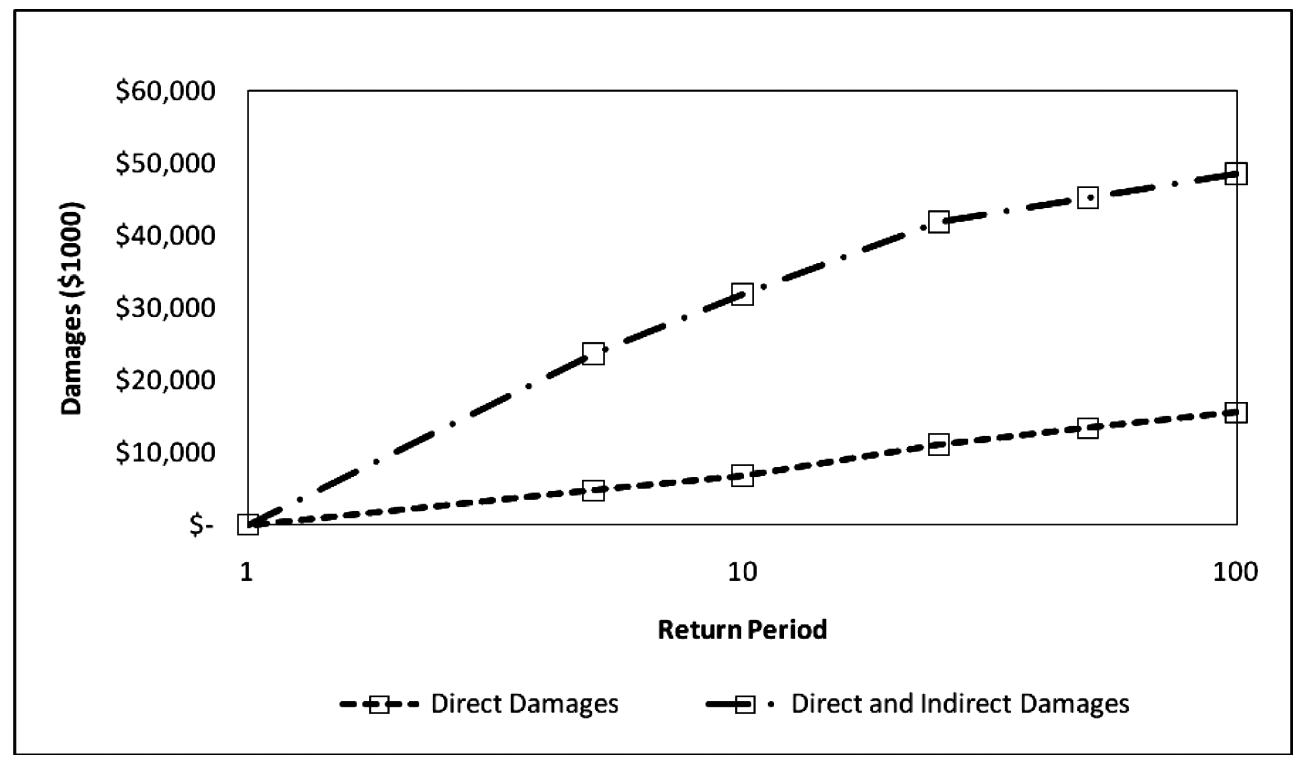

Figure 9: Total flood damages Credit River watershed.

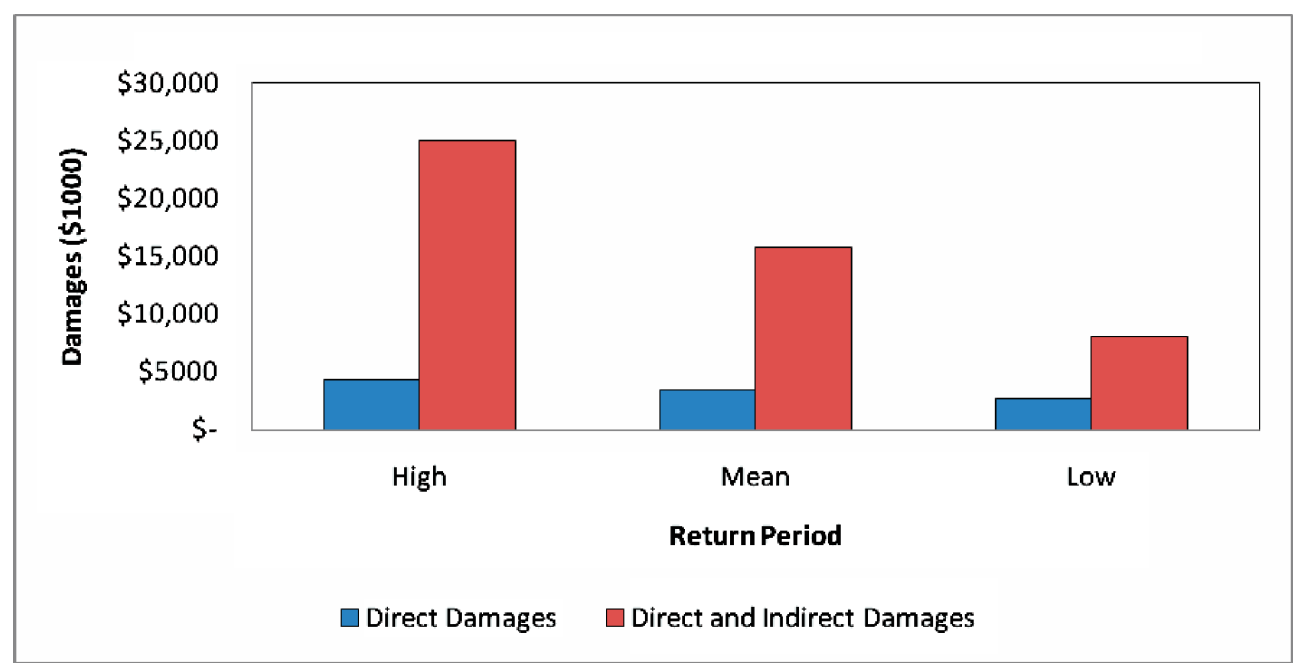

Figure 10: Expected mean annual flood damages, Credit River watershed. 
assuming constant economic conditions. These amounts also represent the mean annual damage risk costs. Figure 11 illustrates the risk index for the flood damage centres for the different return period events. According to Fig. 11, the risk of flooding is higher for the more populated urban areas such as Mississauga and Brampton in the southern portion of the watershed than for the more rural areas in the mid to upper portions of the watershed. It is expected that areas with higher population densities would be at greater risk to flooding, than those areas with lower population densities. In addition, both of these urban centres are located in the lower portion of the watershed, therefore, the volume of flow due to increasing contributing drainage area, is much higher than the volume of flows experienced in the mid to upper portions of the watershed. Furthermore, such areas would have more ready access to emergency services and the resources in dealing with a flood. As a result, their coping capacity would be greater and therefore, can be viewed as being less vulnerable.

Figure 12 illustrates the damage risk costs along the Credit River watershed for varying return periods. The damage risk costs diminish as the return period increases. According to Fig. 12, the mean annual damage risk cost for direct and indirect costs in flood damages is four times as high as for direct damage costs with respect to flood damages. This in turn, diminishes as the return period of the event increases. Despite the relatively high cost in flood damages expected along the Credit River on an annual basis, field observations over the last twenty years have suggested that the actual flood damage costs incurred are significantly lower. In fact, flooding that has typically occurred within the last 20 years along the Credit River has been mostly attributed to the spring freshet and has typically resulted in nuisance flooding. As a result, given the differences between actual field observations and theoretical

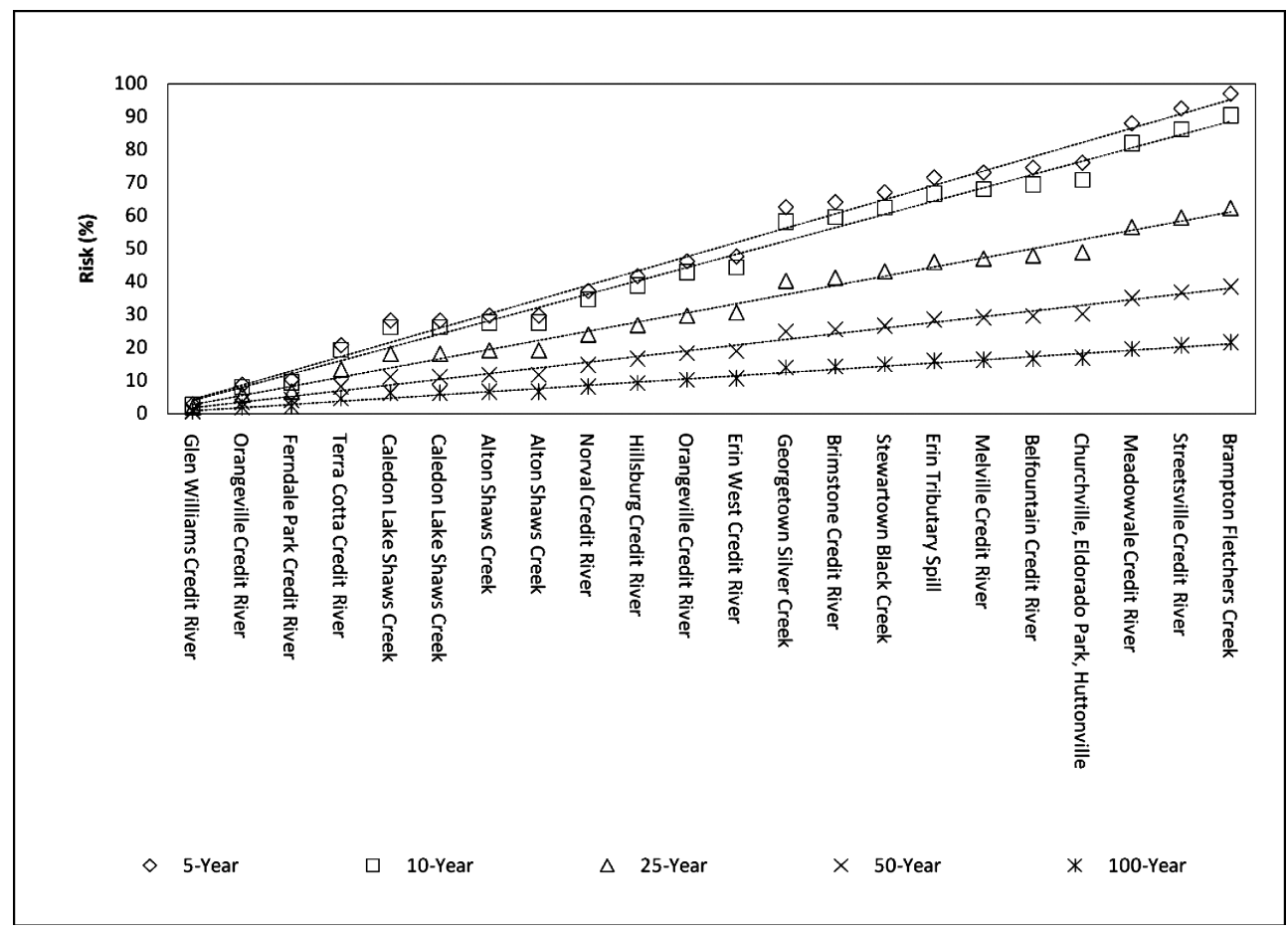

Figure 11: Risk index, Credit River watershed. 


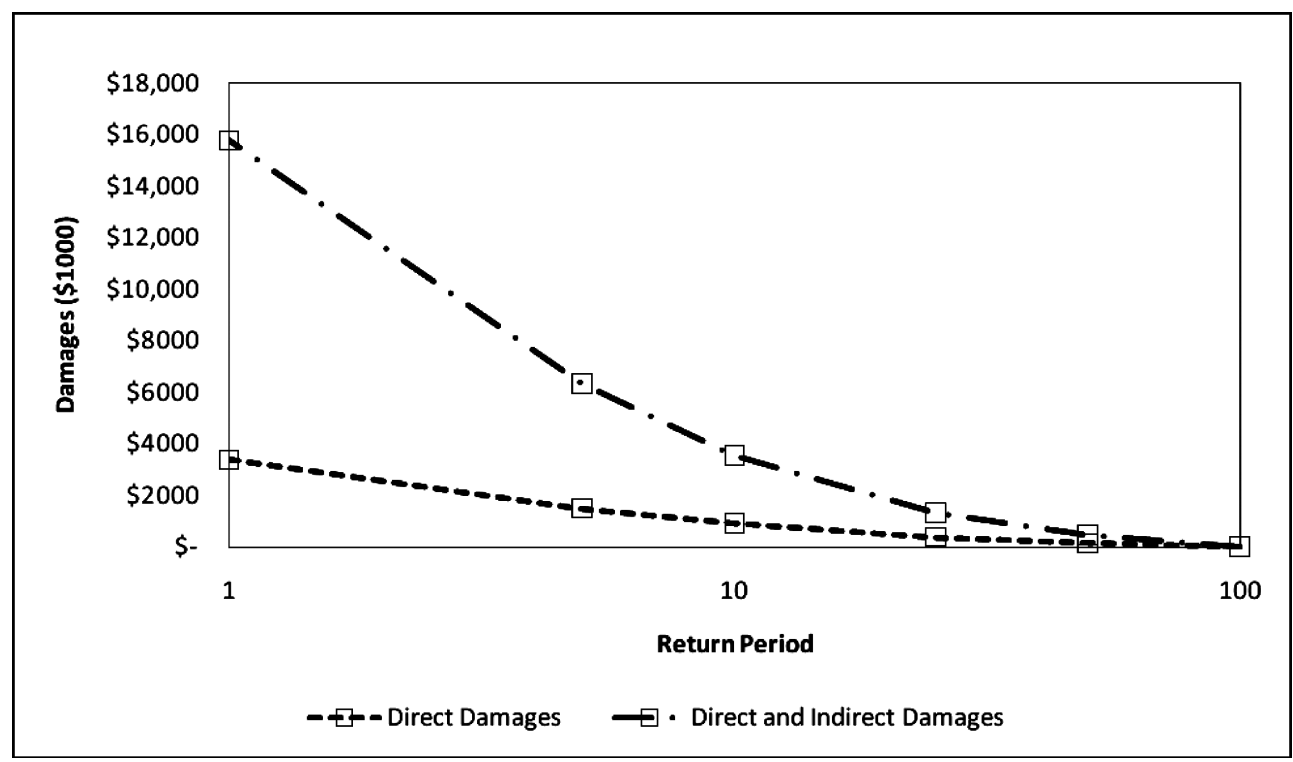

Figure 12: Damage risk costs, Credit River watershed.

modelling results, the costs in flood damages determined here may be used as a planning tool for emergency management, and in the development of any future water management strategies and/or plans.

\section{CONCLUSIONS}

This paper presents a new risk management tool for assessing the vulnerability of communities to flooding, using a combination of Monte Carlo Simulation techniques and multi-criteria analysis. The relationship between the cost in damages and the return period is not linear but logarithmic suggesting that for the more extreme and less frequent events, the impacts to the community would be so severe that any increase in the magnitude of the event would have a negligible impact on the cost in damages. The level of damage to structures within the floodplain is also limited. In the worst-case scenario this would mean complete destruction of all structures within the regulatory floodplain. Indirect costs can have a profound impact on total flood damage costs and can be as high as two to five times direct damage costs. Urban areas are at a higher risk of flooding due to increased population densities, however, such areas are considered to be less vulnerable due to higher coping capacities and resilience to flooding.

For the Credit River Case Study in Ontario, 16 out of the 22 flood damage centres were located within the 5-year event; however, a detailed review of this study showed that the vast majority of flood damages occur between the 100-year event and regulatory flood (Hurricane Hazel), and only half of these structures would experience flooding during the most extreme event(s).

\section{REFERENCES}

[1] UNESCO-IHE, Institute for Water Education, www.UNESCO-IHE-FVI.org.

[2] Flax, L.K., Jackson, W.R. \& Stein, N.D., Community vulnerability assessment tool methodology. Natural Hazards Rev, 3(4), pp. 163-176, 2002. doi:10.1061/ (ASCE)1527-6988(2002)3:4(163) 
[3] UN World Water Development Report 1: Water for People, Water for Life, 2003. Available from: http://www.unesco.org/water/wwap/wwdr/wwdr2.

[4] Plate, E.J., Natural Disasters: Holistic Concept for Recurring Phenomena, Presentation, London, Ontario, November 2004.

[5] Green, C., The evaluation of vulnerability to flooding. Disaster Prevention and Management, 13(4), pp. 323-329, 2004. doi:10.1108/09653560410556546

[6] Hilhorst, D. \& Bankoff, G., Introduction: mapping vulnerability. Mapping Vulnerability: Disasters, Development and People, eds G. Bankoff, G. Frerks \& D. Hilhorst, Earth Scan: Sterling, VA, pp. 1-9, 2004.

[7] Cannon, T., Vulnerability analysis and disasters. Floods ed. D.J. Parker, Routledge: London, pp. 45-55, 2000.

[8] Wisner, B., Blaikie, P., Cannon, T. \& Davis, I., At risk: natural hazards, people's vulnerability and disasters, 2nd edn, Routledge: London, 2004.

[9] Cutter, S.L., Vulnerability to environmental hazards. Progress in Human Geography, 20, pp. 529-539, 1996. doi:10.1177/030913259602000407

[10] Pelling, M., The political ecology of flood hazard in urban Guyana. Geoforum, 30, pp. 249-261, 1999. doi:10.1016/S0016-7185(99)00015-9

[11] McBean, E.A., Gorrie, J., Fortin, M., Ding, J. \& Moulton, R., Flood depth-damage curves by interview survey. Journal of Water Resources Planning and Management, 114(6), pp. 613-33, 1988. doi:10.1061/(ASCE)0733-9496(1988)114:6(613)

[12] Schuster, C.J., Murray, S. \& McBean, E.A., Vulnerability characterization, mapping, and assessment: a study of flooding scenarios for the credit river watershed. Report submitted to Credit Valley Conservation, 2007.

[13] Experian, 2000. Available from: http://www.climatechange.govt.nz/ resources/reports/ economic-impacts-extreme-events-jul04/html/page3.html (Accessed January 2010).

[14] Messner, F. \& Meyer, V., Flood damage, vulnerability and risk perception - challenges for flood damage research. UFZ Discussion Papers, Dept. of Economics 13/2005, 2005.

[15] Lekuthai A. \& Vongvisessomjai S., Intangible flood damage quantification. Water Resources Management, 15, pp. 343-362, 2001. doi:10.1023/A:1014489329348

[16] Cutter, S.L., Boruff, B.J. \&Shirley, W.L., Social vulnerability to environmental hazards. Social Science Quarterly, 84(1), pp. 242-261, 2003. doi:10.1111/1540-6237.8402002

[17] Turner II, B.L., Kasperson, R.E., Matson, P.A., McCarthy, J.J., Corell, R.W., Christensen, L., Eckley, N., Kasperson, J.X., Luers, A., Martello, M.L., Polsky, C., Pulsipher, A. \& Schiller, A., A framework for vulnerability analysis in sustainability science. PNAS (Proceedings of the National Academy of Sciences of the United States of America), 100(14), pp. 8074-8079, 2003. doi:10.1073/pnas.1231335100

[18] Kates, R.W., Hohenemser, C. \& Kasperson J.X. (eds). Perilous Progress: Managing the Hazards of Technology. Westview Press, 1985.

[19] Burton, I. \& Kates, R.W., The Environment as Hazard. Oxford University Press, 1978, 2nd edition with a new introduction, Guilford Press, 1993.

[20] Blaikie, P., Cannon T., Davis I. \& Wisner B., At Risk: Natural hazards, People's vulnerability, and disasters. Routledge: London, 1994.

[21] Hewitt, K., Regions of Risk: A Geographical Introduction to Disasters.Longman: Essex, 1997.

[22] Dwyer, A., Zoppou, C., Nielson, O., Day, S. \& Roberts, S., Quantifying social vulnerability: a methodology for identifying those at risk to natural hazards. Geoscience Australia Record 2004/14, 2004. 
[23] De Almeida, A., Matias Ramos, C., Santos, M.A. \& Viseu, T. (eds). Dam Break Flood Risk Management in Portugal. Laboratorico Nacional de Engenharia Civil: Lisbon, Portugal, 2003 (as found in Plate, 2004).

[24] Adger, W.N., Brooks, N., Bentham, G., Agnew, M. \& Eriksen, S., New indicators of vulnerability and adaptive capacity. Tyndall Centre Technical Report 7, Tyndall Centre for Climate Change Research Norwich, UK, 2004.

[25] Tapsell, S.M., Penning-Roswell, E.C., Tunstall, S.M. \& Wilson, T.L., Vulnerability to flooding: health and social dimensions. Phil. Trans. R. Soc. Lond A 360, pp. 1511-25, 2002. doi:10.1098/rsta.2002.1013

[26] Townsend, P., Phillimore, P. \& Beattie, A., Health and Deprivation: Inequality and the North, Croom Helm: London, 1988.

[27] Carstairs, V. \& Morris, R., Deprivation and Health in Scotland. Aberdeen University Press: Aberdeen, 1991.

[28] Rygel, L., O’Sullivan, D. \& Yarnal, B., A method for constructing a social vulnerability index. Submitted to Mitigation and Adaptation Strategies for Global Change, 2005.

[29] St. Bernard G., Towards the construction of a social vulnerability index - theoretical and methodological considerations. Submitted to Journal of Social and Economic Studies, 2003.

[30] Bankoff, G., Cultures of Disaster: Society and Natural Hazards in the Philippines, Routledge and Curzon: London, 2003.

[31] Credit Valley Conservation Authority (CVCA), Credit River Water Management Strategy: Phase I Report, 1990.

[32] Environmental Water Resources Group Limited \& Doherty C., Floodline Mapping of the Main Credit River, Consulting Report for Credit Valley Conservation Authority, 2007.

[33] Phillips Planning and Engineering Ltd., Credit River Flood Damage Reduction Study, Consulting Report for Credit Valley Conservation Authority, 1985.

[34] Wu, S.Y., Yarnal, B. \& Fisher, A., Vulnerability of coastal communities to sea-level rise: a case study of Cape May County, New Jersey, USA. Climate Research, 22(44). pp. 255-270, 2002. doi:10.3354/cr022255 